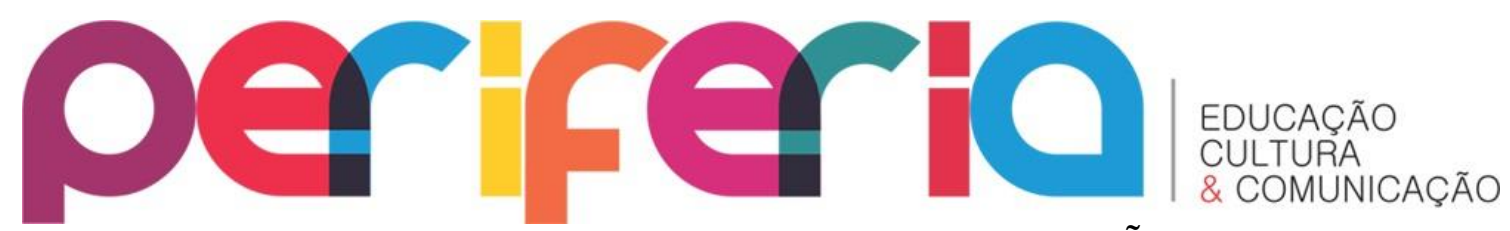

\title{
DEUS E O DIABO NA PRATELEIRA DO MERCADO: REFLEXÕES E NARRATIVAS DE UM RACISMO RELIGIOSO VIGENTE
}

\section{GOD AND THE DEVIL ON THE MARKET SHELF: REFLECTIONS AND NARRATIVES OF PREVAILING RELIGIOUS RACISM}

\author{
Marcos Eduardo Leandro ${ }^{1}$ \\ Lúcio Bernard Sanfilippo²
}

\begin{abstract}
RESUMO: No primeiro semestre do ano de 2017, testemunhamos uma crescente onda de violência se abatendo sobre terreiros de candomblé por todo o Brasil, mais ainda em Nova Iguaçu, cidade da Baixada Fluminense, na periferia do Rio de Janeiro. Os autodenominados traficantes de Cristo, cientes da impunidade, invadiram, depredaram terreiros e agrediram sacerdotes e sacerdotisas em suas comunidades tradicionais de matrizes africanas. Analisando fatores históricos - pois que esses fatos sempre estiveram presentes nos cotidianos dos cultos afro-brasileiros, a trajetória do racismo religioso e o crescimento das igrejas neopentecostais em todo país, refletimos sobre essa violência e suas implicações nos contextos políticos e culturais da atual conjuntura. De acordo com as narrativas que levam à demonização das religiões de matriz africana, onde se prega que "a Umbanda, Quimbanda, Candomblé e o espiritismo de um modo geral, são os principais canais de atuação dos demônios, principalmente em nossa pátria" (Macedo, 1987, p. 113), presenciamos um projeto de poder político-institucional que viola direitos humanos e constitucionais, além de estarem alinhados a setores conservadores e obscurantistas da sociedade.
\end{abstract}

PALAVRAS-CHAVE: Racismo religioso. Ensino religioso. Crianças de terreiro. Religião de matriz africana. Candomblé.

ABSTRACT: In the first half of 2017, we witnessed a growing wave of violence involving candomblé earthquakes throughout Brazil, especially in Nova Iguaçu, a city in the Baixada Fluminense, on the outskirts of Rio de Janeiro. The self-styled Christ-traffickers, conscious of impunity, invaded, destroyed terreiros and priests and priestesses attacked in their traditional African matrix communities. Analyzing the historical factors - since these facts have always been present in the daily life of Afro-Brazilian cults - the trajectory of religious racism and the

\footnotetext{
${ }^{1}$ Ator e Professor de Artes Cênicas na SME (Secretaria Municipal de Educação do RJ) e na SEEDUC (Secretaria de Estado de Educação do RJ). Formado em licenciatura em artes cênicas pela UNIRIO, com atuação no Núcleo de Estudos das Performances Afro-Ameríndias (NEPAA). Bolsista no Summer Course Tisch School - NYU (New York University): "Performance e Política no Peru", em Lima (2017). Colaborador no NEAB-LEAFRO (UFRRJ). Mestre e doutorando em educação, pela UERJ. Participa do Grupo de Pesquisa Kékéré, coordenado pela $\operatorname{Prof}^{a} \operatorname{Dr}^{a}$ Stela Caputo, onde pesquisamos o protagonismo de crianças nos terreiros de Candomblé (Jeje-nagô e Bantu).

${ }^{2}$ Programa de Pós-graduação em Educação da Universidade do Estado do Rio de Janeiro (ProPEd/UERJ)
} 


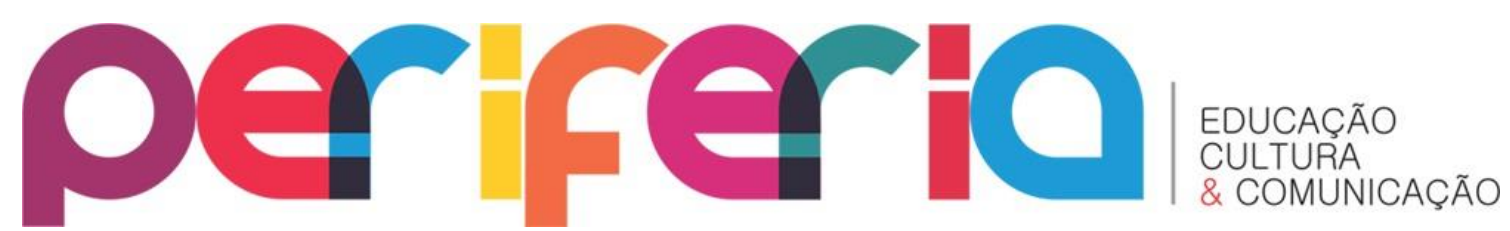

growth of the neo-Pentecostal churches in all countries, we reflect on this violence and its implications on politics and contexts of the current conjuncture. According to the narratives that have led to the demonization of African religions, where it is preached that "Umbanda, Quimbanda, Candomblé and spiritism in general are the main channels for the performance of demons, especially in our homeland" (Macedo, 1987, p. 113) a project of political-institutional power that violates human and constitutional rights, in addition to being aligned with conservative and obscurantist sectors of society.

KEYWORDS: Religious racism. Religious education. Children of terreiro. African matrix religion. Candomblé

\begin{abstract}
"Devemos lembrar que os povos afrodescendentes estão entre os mais afetados pelo racismo. Muitas vezes, eles têm seus direitos básicos negados, como o acesso a serviços de saúde de qualidade e educação."
\end{abstract}

\title{
BAN KI-MOON
}

Secretário-geral das Nações Unidas

Década Internacional dos Afrodescendentes (2015-2024).

O racismo religioso está presente na história do Brasil desde a chegada do colonizador português. Nas primeiras missões, no percurso inaugurado pela catequese, havia a nítida intenção, através do sacerdócio dos jesuítas, em demonizar e converter indígenas e africanos ao cristianismo, mais especificamente à religião católica. Ao longo dos séculos a catequização se perpetuou em nosso país através da conversão religiosa e, fundamentalmente, das políticas de um Estado associado diretamente à igreja.

Entretanto, nos perguntamos: o que seria, neste contexto, a denominação "racismo religioso"?

Antes de refletirmos brevemente sobre tal conceito, vale a pena abordarmos alguns aspectos que se constituíram nas tensões entre setores das igrejas evangélicas e comunidades tradicionais de matrizes africanas.

\section{O acirramento das perseguições religiosas}

"Vai queimar no inferno". Foi o que uma voz ameaçadora esbravejou para a menina de 11 anos de idade, no momento em que ela percebeu o sangue escorregando pelo rosto, avermelhando toda sua veste branca. Foi numa noite de domingo, em junho de 2015, que a menina Kaylane Campos, moradora da Vila da Penha (RJ), levou uma pedrada na cabeça vinda de um grupo que, com bíblias em punho, a insultava e a seus familiares, por serem do candomblé. $\mathrm{O}$ caso da menina Kaylane repercutiu nacional e internacionalmente. 


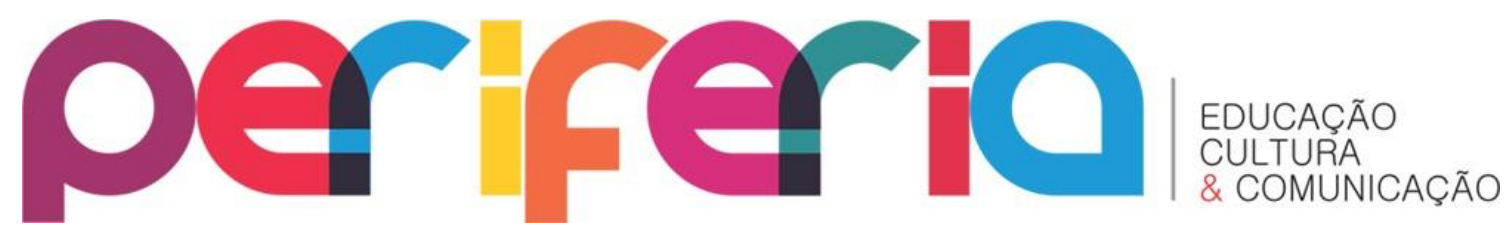

Em agosto de 2017, Maria da Conceição Cerqueira da Silva, 65 anos, moradora de Nova Iguaçu, na Baixada Fluminense (RJ), foi agredida à pedrada próxima a sua casa. Segundo sua filha Eliane Nascimento da Silva, de 42 anos, ao sair para ir ao mercado, Dona Maria ouviu sua vizinha gritar: "lá vem essa velha macumbeira. Hoje eu acabo com ela". Em seguida, a senhora foi atingida por pedradas. A idosa teve ferimentos no rosto, na boca e no braço e foi levada para o Hospital Geral de Nova Iguaçu (HGNI).

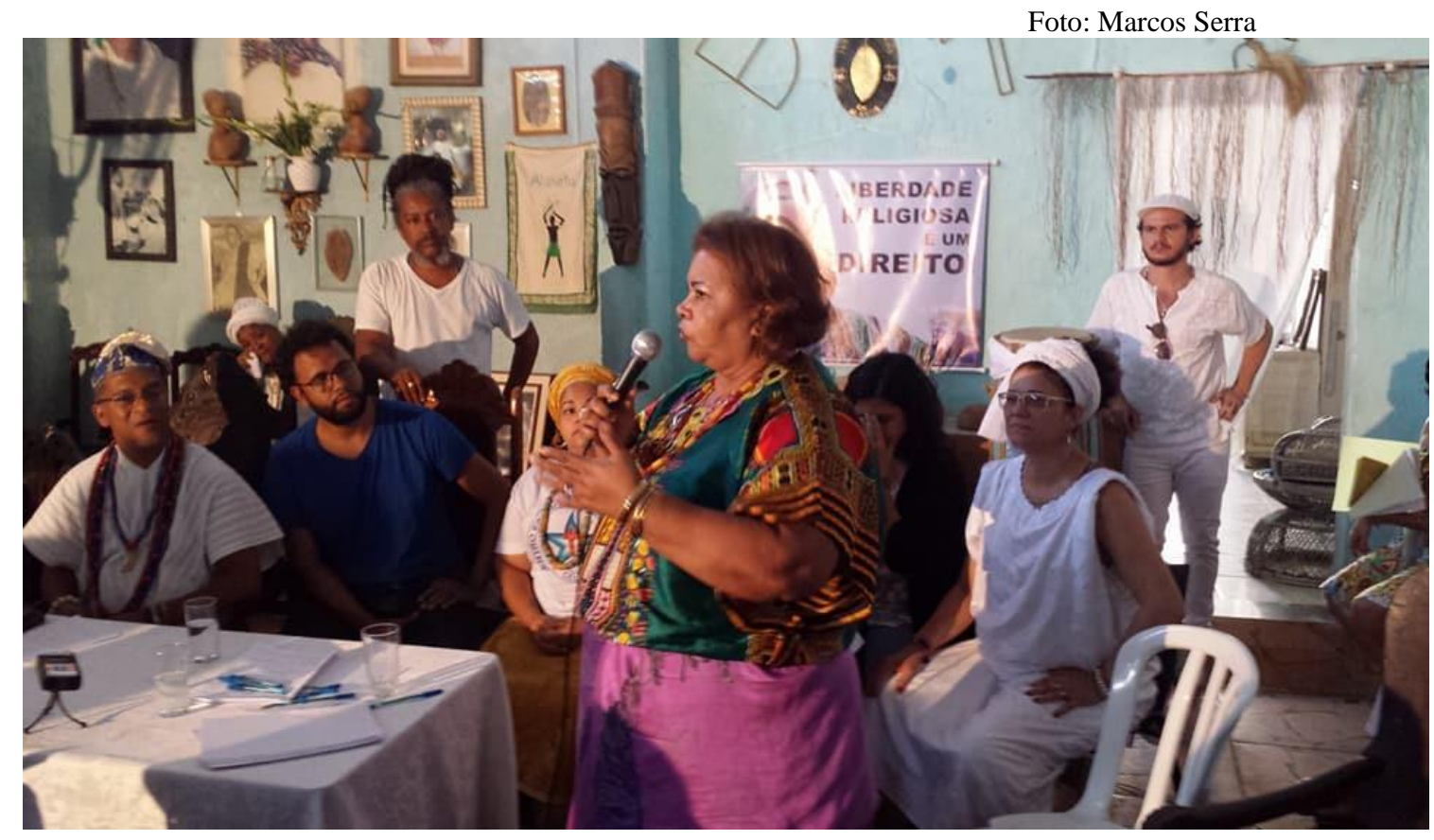

Também em agosto de 2017, a Yalorixá Carmen de Oxum (foto), ficou nacionalmente conhecida a partir de um vídeo divulgado na internet, onde traficantes do bairro Miguel Couto, em Nova Iguaçu, obrigaram-na a destruir seus objetos sagrados enquanto filmavam toda a ação e ameaçavam matar seus filhos, caso não destruísse seus assentamentos sagrados.

Os casos supracitados, infelizmente, são alguns dentre centenas que ocorreram ao longo das primeiras décadas do século XXI. A partir da "Carta dos povos tradicionais de matriz africana do Estado do Rio de Janeiro"3", encaminhada em audiência pública à ALERJ (Assembleia Legislativa do Estado do Rio de Janeiro) em 05/10/2017, percebemos que:

No Rio de Janeiro desde 2006 a imprensa vem noticiando a proibição, por parte de traficantes, a terreiros em todo Estado. Em 2008, reportagens dos jornais Extra e $\mathrm{O}$ Dia traziam manchetes que anunciavam a atuação do traficante Fernandinho Guarabu que vinha fechando os terreiros de Umbanda e Candomblé no Morro do Dendê, na Ilha do Governador, Zona Norte da

\footnotetext{
${ }^{3}$ Visto: http://s0.ejesa.ig.com.br/pdf/odia/17/10/CARTA-TERREIRO-RJ-audiencia-publica.pdf>
} Acesso em: 20/10/2017.

Revista Periferia, v.10, n.1, p. 89 - 99, Jan./Jun. 2018 


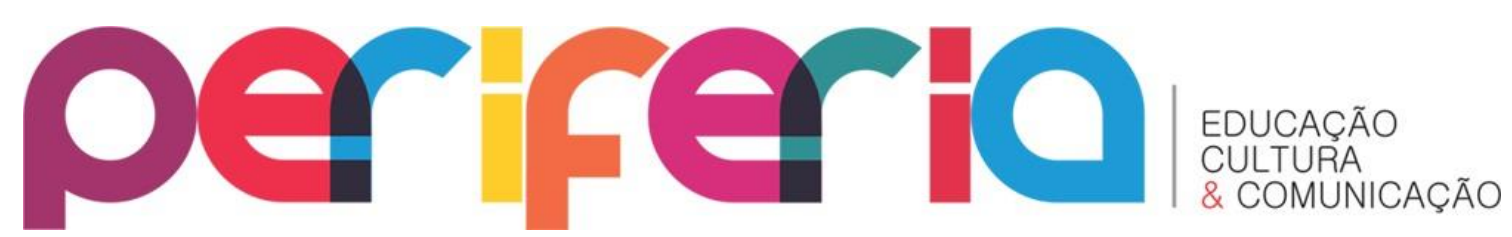

cidade do Rio. Em 2014, a imprensa novamente noticiou a mesma atuação, desta vez, por traficantes do Complexo do Lins, também na zona norte do Rio, que expulsavam adeptos do Candomblé.

Além da carta-denúncia, outro encaminhamento dado pela Secretaria de Estado de Segurança (SESEG) e pela Secretaria de Estado de Assistência Social e Direitos Humanos (SEASDH), a partir da articulação de lideranças de religiões de matriz africana, foi a antecipação da criação da Delegacia de Crimes Raciais e Delitos de Intolerância (DECRADI). O órgão se propõe a agilizar e a apurar, especificamente, crimes de cunho religioso que têm dificuldade de serem acolhidos pelas delegacias comuns.

$\mathrm{O}$ racismo religioso neopentecostal, reflete um problema de toda a sociedade brasileira: o completo desconhecimento da história africana, afro-brasileira, indígena e afro-ameríndia.

Desinformação e preconceitos, geraram uma cultura de ódio retroalimentada pelo racismo. Se observarmos como se processa a educação no "chão da escola", nos questionaremos: o que aprendemos? Como aprendemos? Quais são os povos, etnias e matrizes culturais predominantes nos currículos?

O pouco que conhecemos da história e cultura afro-brasileira, africana, indígena e afroameríndia, são contadas sob o ponto de vista do colonizador, são eurocêntricos. Por isso Munanga (2005) nos orienta:

O resgate da memória coletiva e da história da comunidade negra não interessa apenas aos alunos de ascendência negra. Interessa também aos alunos de outras ascendências étnicas, principalmente branca, pois ao receber uma educação envenenada pelos preconceitos, eles também tiveram suas estruturas psíquicas afetadas. Além disso, essa memória não pertence somente aos negros. Ela pertence a todos, tendo em vista que a cultura da qual nos alimentamos quotidianamente é fruto de todos os segmentos étnicos que, apesar das condições desiguais nas quais se desenvolvem, contribuíram cada um de seu modo na formação da riqueza econômica e social e da identidade nacional (pag.16).

Uma nova onda de depredações e invasões de terreiros se configurou neste ano de 2017, principalmente em Nova Iguaçu, na Baixada Fluminense. Além da violação dos espaços sagrados, "traficantes de Cristo", utilizam-se de práticas terroristas para expulsar sacerdotisas e sacerdotes de matrizes africanas de seus terreiros, com a mesma alegação e discurso difundidos nos cultos de diversas igrejas neopentecostais, nos bairros periféricos e nas escolas públicas. São discursos de ódio e intolerância que classificamos como racismo religioso, sobretudo por entendermos que essa categoria se estruturou em nosso país operando na perspectiva de que tudo relacionado ao "negro torna-se, então, sinônimo de ser primitivo, inferior, dotado de uma mentalidade pré-lógica” (MUNANGA 2012, p. 24). Não é por acaso que, em nossa educação, somos levados a enxergar comunidades tradicionais de matrizes africanas e/ou indígenas como espaços primitivos, territórios e pessoas desprovidas de "desenvolvimento" social e humano, "idólatras" em suas concepções de mundo e religiosidades. Esse olhar ultrapassa os cânones

Revista Periferia, v.10, n.1, p. 89 - 99, Jan./Jun. 2018 


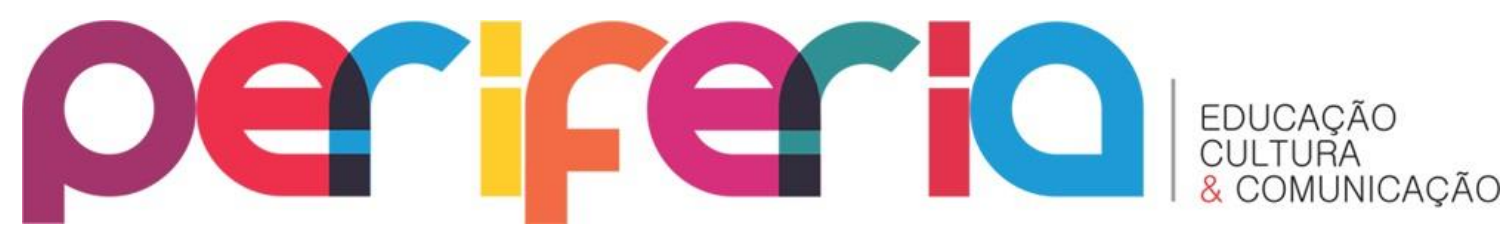

proselitistas da conversão religiosa, pois trata-se de um discurso excludente e de uma prática terrorista contemporânea. Diante disso, faz-se necessário compreendermos os aspectos políticos, históricos e educativos que nos trouxeram a esse momento obscurantista da política brasileira.

\section{O mercado popular: fé para dar e vender}

No neopentecostalismo, verificamos amplamente, em diversos contextos culturais, uma adaptação grotesca da cosmovisão cristã na Idade Média europeia, que chega ao Brasil com os católicos portugueses e se perpetua até os nossos dias. Nessa concepção, elencamos alguns aspectos a respeito dos quais vimos refletindo:

1) Uma visão de mundo maniqueísta, que concebe relações humanas, atitudinais, pautadas entre a influência de demônios (espíritos maus) e do deus único, associado ao bem-estar, a ordem e ao sucesso;

2) Toda e qualquer visão de mundo contrária a essa "lógica" tem associação direta com o mal;

3) Não há espaço para quaisquer discussões sobre diversidades culturais, direitos e valores civilizatórios que não sejam pautados pela cosmovisão cristã, ou seja, não existindo argumentos, prevalece a "palavra de deus";

4) A bíblia (livro sagrado dos cristãos) opera como "carta magna", a única constituição a ser seguida. Qualquer argumento contrário a ela será devolvido como heresia.

Não nos interessa, neste momento, refletir sobre as crenças no diabo e seus respectivos demônios, propagadas pela religiosidade judaico-cristã. Refletiremos sobre a subjetividade dos discursos, seus aspectos conservadores, mercantis e na crença difundida entre os sujeitos pertencentes às religiões neopentecostais: que os seus problemas, em especial os de ordem financeira, serão causados pelos agentes demoníacos residentes nas "falsas religiões", em especial, as religiões de matriz africana.

O fundador da Igreja Universal do Reino de Deus (IURD) nos diz o seguinte:

Tudo o que existe de ruim neste mundo têm sua origem em satanás e seus demônios. São eles os causadores de todos os infortúnios que atingem o homem direta ou indiretamente [...] Qual a origem de todos os males que afligem a humanidade? Doenças, misérias, desastres e todos os problemas que tem afligido o homem desde que este iniciou sua vida na terra, tem uma origem: o diabo (Macedo, 1987: 103).

Revista Periferia, v.10, n.1, p. 89 - 99, Jan./Jun. 2018 


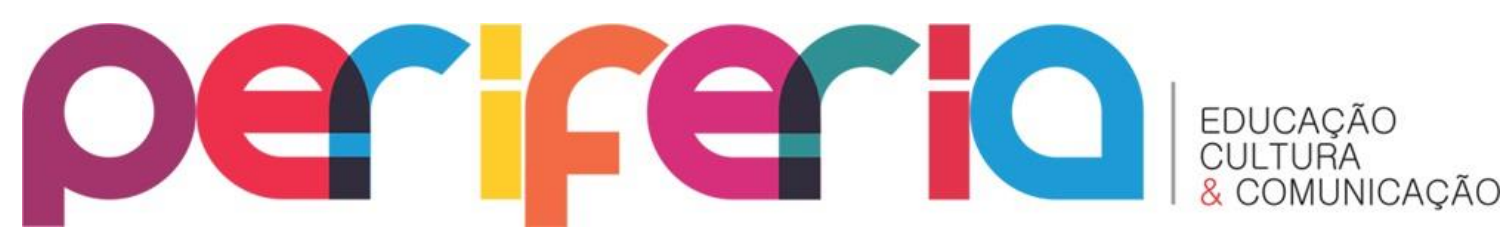

Observamos um projeto de poder político-financeiro, subscrito pela guerra entre deus e o diabo, bem como furiosos embates por uma hegemonia religiosa que se revela em torno daquilo que nomearemos como "mercado da fé".

As religiões cristãs neopentecostais, principais promotoras das violências verbais, físicas e epistemológicas em relação às comunidades tradicionais de matrizes africanas, agenciam uma verdadeira "disputa espiritual". Nessa estrutura maniqueísta, resultado desta disputa entre "deus e o diabo", o bem e o mal, é possível identificarmos um "mercado da fé" pronto a negociar a "salvação" das almas de dissidentes e recém-convertidos. De acordo com Oro (1997):

\begin{abstract}
Em primeiro lugar, como explico mais à frente, estamos diante de expressões religiosas que disputam fiéis que compartilham além do mesmo nível social, dos mesmos códigos simbólicos e cognitivos. Em consequência temos, de um lado, a conversão de umbandistas, até mesmo de pais e mães-de-santo e, de outro lado, pastores da Universal que precisam dominar, conhecer, os códigos das religiões afro-brasileiras para acederem aquele cargo. Em segundo lugar, verificamos a ocorrência de uma disputa por iguais que se encontram no meio urbano. De fato, como mostraram Pierucci e Prandi (1996), 42,2\% dos pentecostais, 70,6\% dos freqüentadores das religiões afrobrasileiras e $52,6 \%$ dos kardecistas, estão implantados nas capitais e regiões metropolitanas do país. Enfim, e não menos importante, a concorrência religiosa movida pelo neopentecostalismo não significa a negação do afrobrasileiro (pag. 16)
\end{abstract}

Pensando com o professor e antropólogo, os ataques às comunidades tradicionais de matrizes africanas obedecem a uma lógica mercadológica de bens e serviços simbólicos, o que difere, em última análise, daquilo que observamos historicamente com o catolicismo e sua catequese: "o embate estaria ocorrendo simetricamente entre iguais" (ibidem). Não se trata de "luta de classes", nem mesmo de grupos étnicos antagônicos que disputam uma "supremacia". Muito embora reconheçamos o racismo nas práticas cotidianas dessas agremiações, sabemos que suas bases, seus contingentes, são em maioria formados por negros (as) pobres e moradores (as) de periferias.

Curiosamente, não há uma negação do poder das divindades africanas e afro-brasileiras, seus rituais e seus territórios, ao contrário. Ao afirmar a existência e o poder das divindades africanas, estrategicamente, elas são posicionadas enquanto algozes do desenvolvimento e da prosperidade do ser humano, o que é representado, em primeira instância, por Satanás e seus demônios. Além disso, nos parece existir um apelo sistemático em modificar os signos e significados rituais afro-ameríndios em subprodutos remodelados à fé neopentecostal, sendo inclusive negociado em valores monetários reais.

A demonização da religião de matriz africana, mesmo não tendo relação alguma com o diabo cristão, potencializa a evasão de seguidores. O crescente poder midiático (TV, rádio, jornais etc.) da IURD e demais igrejas neopentecostais, não determinam a manutenção das comunidades de terreiro, mas as coloca como antagonista da prosperidade, da beleza, da riqueza, da relação com o criador.

Revista Periferia, v.10, n.1, p. 89 - 99, Jan./Jun. 2018 


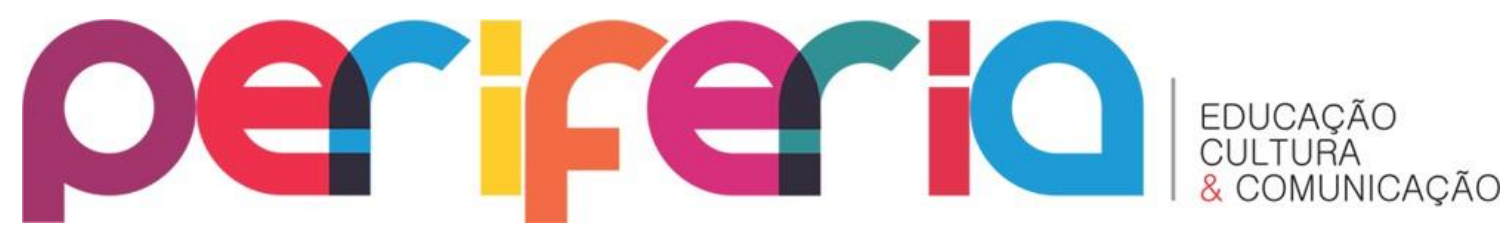

Com nomes bonitos e cheios de aparatos, os demônios vêm enganando as pessoas com doutrinas diabólicas. Chamam-se orixás, caboclos, pretos velhos, guias, espíritos de luz, etc. Dizem-se ser exus, erês, espíritos de crianças, médicos famosos, poetas famosos, etc., mas na verdade são anjos decaídos (Macedo, 1987: 32).

No mercado popular-religioso a disputa é travada entre os "pares sociais", de nível econômico e etnia semelhantes: pretos (as), pobres e periféricos (as), artífices de um projeto de poder que se desenha no Brasil nos últimos trinta anos. O poder financeiro, midiático e políticoeleitoral das igrejas neopentecostais, agora organizado na chamada "bancada evangélica", no Congresso Nacional, vem crescendo em proporções consideráveis a cada pleito. Neste cenário, crescem também políticas austeras contrárias à liberdade de direitos e as conquistas sociais, além de extremamente conservadoras. Paralelo a isso, o secundário poder político que as religiões de matriz africana têm a seu favor, sequer lhes garante subsídios para se defenderem.

O racismo nos ensina que a participação de negros (as) na política partidária: representações executivas e legislativas, são ínfimas, se comparadas à densidade demográfica. Na mesma medida, às religiões de matriz africana faltam representações políticas, uma realidade que incidirá diretamente na ausência de políticas públicas que salvaguardem o direito constitucional à liberdade de culto.

\section{"Não tem nem diabo aqui..."}

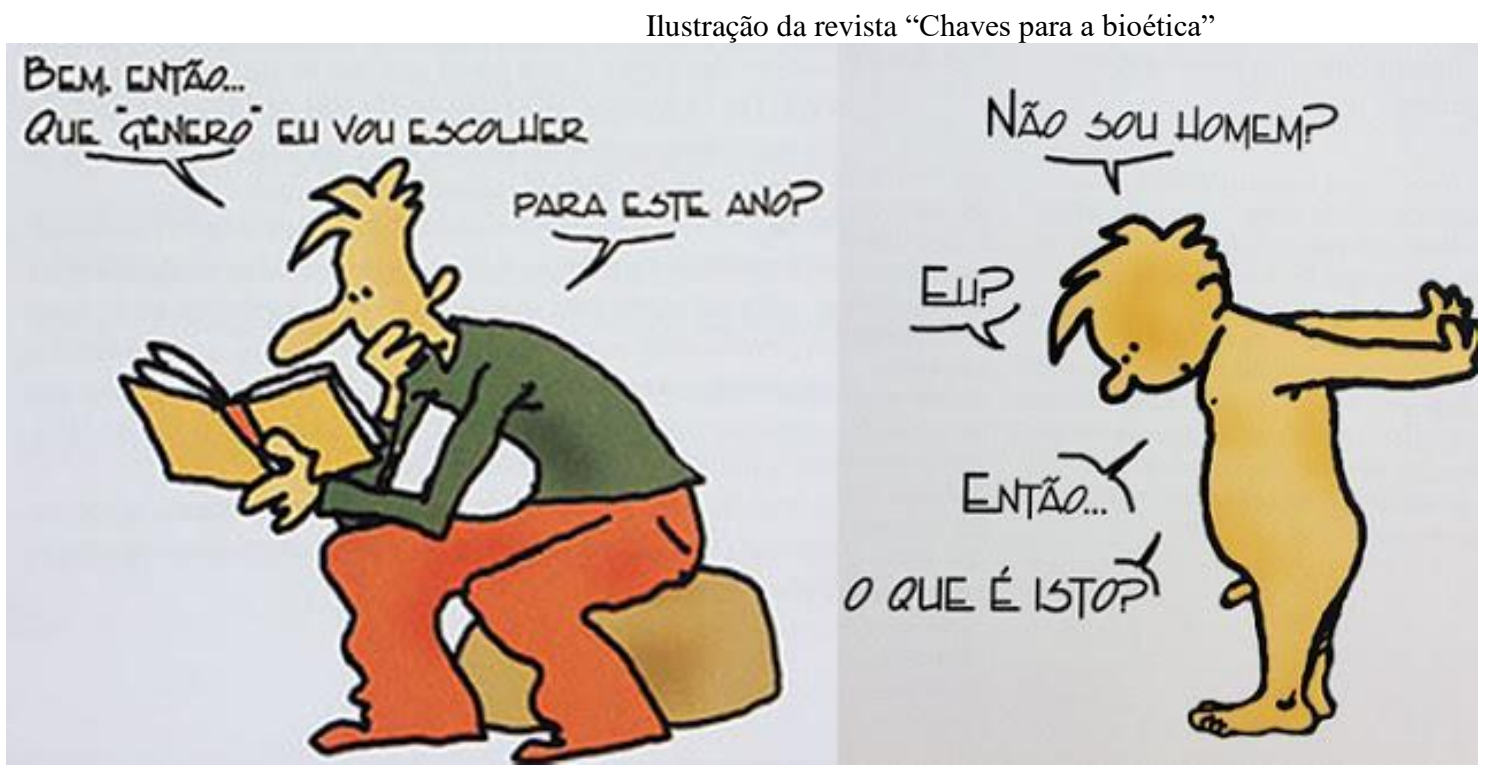

Revista Periferia, v.10, n.1, p. 89 - 99, Jan./Jun. 2018 


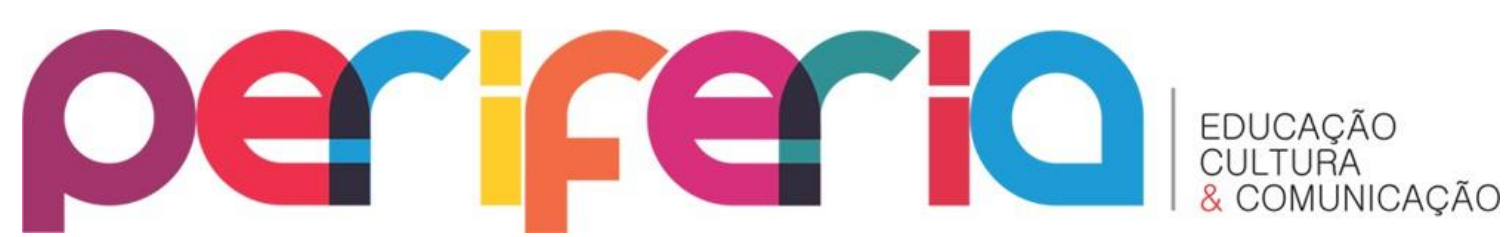

No dia 27 de setembro de 2017, dia em que o catolicismo comemora os santos Cosme e Damião e algumas religiões de matriz africana comemoram o dia de Ibeji ${ }^{4}$, dos Erê (crianças), em votação apertada - 06 votos a 05 - o Supremo Tribunal Federal (STF) rejeitou a Ação Direta de Inconstitucionalidade (ADI) 4439, decidindo que o ensino religioso nas escolas públicas pode ter natureza confessional, isto é, que as aulas podem seguir os ensinamentos de uma religião específica ${ }^{5}$. Na prática isso significa que um professor católico (ou evangélico), por exemplo, poderá catequizar os seus alunos. Inevitavelmente, essa modalidade que foi aprovada irá contribuir para o aumento da discriminação de crianças de religiões de matriz africana nas escolas, uma vez que percebemos em nossas pesquisas com crianças de terreiros, que a escola é um dos espaços mais cruéis no que diz respeito ao racismo religioso (CAPUTO 2012, p. 216217).

O racismo religioso sempre contou com poderosos mecanismos institucionais, um dos principais é o ensino religioso. Tratando-se de um projeto conservador de poder, onde a laicidade é posta em xeque, o resultado, mesmo em votação apertada, era de se esperar. $\mathrm{O}$ ministro decano da suprema corte, Juiz Celso de Mello, declarou:

\begin{abstract}
"O ensino religioso nas escolas públicas não pode nem deve ser confessional ou interconfessional, pois a não confessionalidade do ensino religioso na escola pública traduz consequência necessária do postulado inscrito na nossa vigente Constituição, da laicidade do Estado Republicano brasileiro"
\end{abstract}

Observamos a decisão contraditória do STF quando analisamos a redação da Ação Direta de Inconstitucionalidade (ADI) 4439. Um parecer que, em sua introdução ${ }^{7}$, nos alerta:

A Constituição da República consagra, a um só tempo, o princípio da laicidade do Estado (art. 19, I) e a previsão de que "o ensino religioso, de matrícula facultativa, constituirá disciplina dos horários normais das escolas públicas de ensino fundamental" (art. 210, $\S 1^{\circ}$ ). [...] A escola pública não é lugar para o ensino religioso confessional e também para o interconfessional ou ecumênico, pois este, ainda que não voltado à promoção de uma confissão específica, tem por propósito inculcar nos alunos princípios e valores

\footnotetext{
${ }^{4}$ Divindades gêmeas infantis, ligadas a todos os orixás e seres humanos. Por serem gêmeos, são associados ao princípio da dualidade, por serem crianças, são ligados a tudo que se inicia e nasce.

${ }^{5}$ Visto em: <http://agenciabrasil.ebc.com.br/educacao/noticia/2017-09/supremo-autoriza-ensinoreligioso-confessional-nas-escolas-publicas> Acesso: 21/10/2017.
}

${ }^{6}$ Ibidem

\footnotetext{
${ }^{7}$ Visto em:

<file:///C:/Users/usu\%C3\%A1rio/Desktop/doutorado/ADI\%204439\%20ENSINO\%20RELIGIO SO\%20CONFESSIONAL.pdf $>$ Acesso: 23/10/2017.
}

Revista Periferia, v.10, n.1, p. 89 - 99, Jan./Jun. 2018 


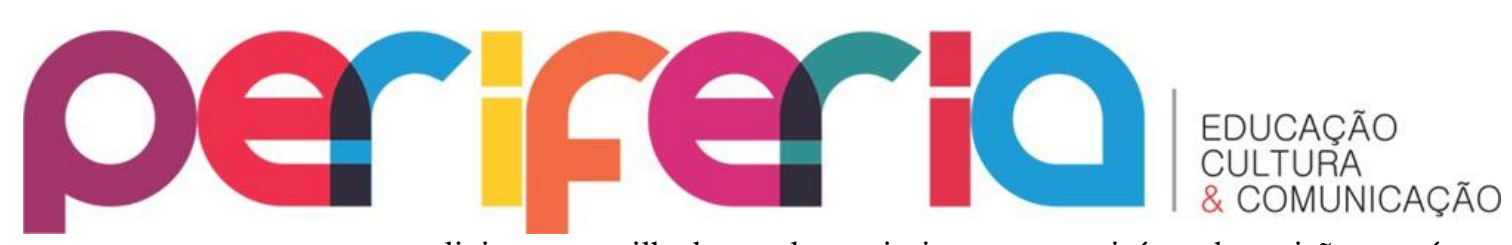

religiosos partilhados pela maioria, com prejuízo das visões ateístas, agnósticas, ou de religiões com menor poder na esfera sócio-política ${ }^{8}$.

A frase "Não tem nem diabo aqui...", foi dita pela menina Ana Clara Pereira no vídeo "Crianças de terreiros, redes educativas e diferenças" ${ }^{\text {, }}$ produzido pelo Grupo de Pesquisa Kékeré, do ProPEd/UERJ (Programa de Pós-graduação em Educação da Universidade do Estado do Rio de Janeiro), coordenado pela professora Stela Guedes Caputo, lançado na Audiência Pública: Intolerância Religiosa e Ataques a Terreiros, na ALERJ, no dia 05 de outubro de 2017. Uma narrativa que exprime a imensidão de sentidos e sentimentos de muitas crianças e adolescentes das tradicionais de matrizes africanas. Muitas de dessas crianças, que amam sua religião, suas divindades, que convivem plenamente os cotidianos de suas comunidades de terreiro, são obrigadas a negarem sua fé, suas crenças, suas origens. Crianças que optam em dizerem-se evangélicas para serem aceitas na escola, traçam uma estratégia de sobrevivência que nega o seu sagrado e mutila suas identidades. Acreditamos que o racismo religioso, bem como as pedradas atiradas na menina Kaylane e em Dona Maria da Conceição, atinjam muito mais do que, assustadoramente, está explícito.

A escola, que deveria funcionar como um território de combate à ignorância e toda forma de opressão, terá permissão oficial para reforçar a discriminação entres as crianças e jovens que não professem a fé cristã. O espaço/tempo para desenvolvimento dos seres e suas potencialidades, para a convivência da diversidade, acabará servindo - como já vem ocorrendo - para que se acentuem ainda mais as marcas do racismo religioso e da discriminação.

Utilizamos neste tópico uma imagem contida na cartilha católica "Chaves para a bioética" distribuídas à professores da rede estadual de ensino do Rio de Janeiro durante o X Fórum de Ensino Religioso, realizado no fim de março de 2014. O material, que, segundo o Ministério Público (MP), é de conteúdo homofóbico e machista ${ }^{10}$, foi entregue a milhares de participantes da Jornada Mundial da Juventude (JMJ), evento católico que teve sua edição, no ano de 2013, na cidade do Rio de Janeiro. Na ocasião, foram impressos cerca de 2 milhões de exemplares do guia em quatro idiomas - 900 mil apenas em português -, com produção da fundação católica Jérôme Lejeune e da Comissão Nacional da Pastoral Familiar da Conferência Nacional dos Bispos do Brasil (CNBB). Entretanto, por determinação do MP, a partir da denúncia feita pelo grupo de pesquisa Ilè Obà Òyó ${ }^{11}$ (atual Grupo Kékerée ${ }^{12}$ ) do Programa de Pós-graduação da Universidade do Estado do Rio de Janeiro (ProPEd/UERJ), a Secretaria de Estado de Educação do Rio de Janeiro (SEEDUC-RJ) recolheu as cartilhas católicas. Para nós

\footnotetext{
${ }^{8}$ Ibidem

${ }^{9}$ Visto em: < https://www.youtube.com/watch?v=0-PEVAyl8I0> Acesso: 19/10/2017.

${ }^{10}$ Visto: <https://oglobo.globo.com/sociedade/educacao/por-ordem-do-mp-governo-do-riorecolhe-cartilhas-homofobicas-suspende-foruns-religiosos-14648765> Acesso em: 23/10/2017.

${ }^{11}$ Casa do Rei de Oyó (Xangô - Orixá da justiça)

${ }^{12}$ Em tradução livre do idioma yorubá: pequeno, miúdo.
}

Revista Periferia, v.10, n.1, p. 89 - 99, Jan./Jun. 2018 


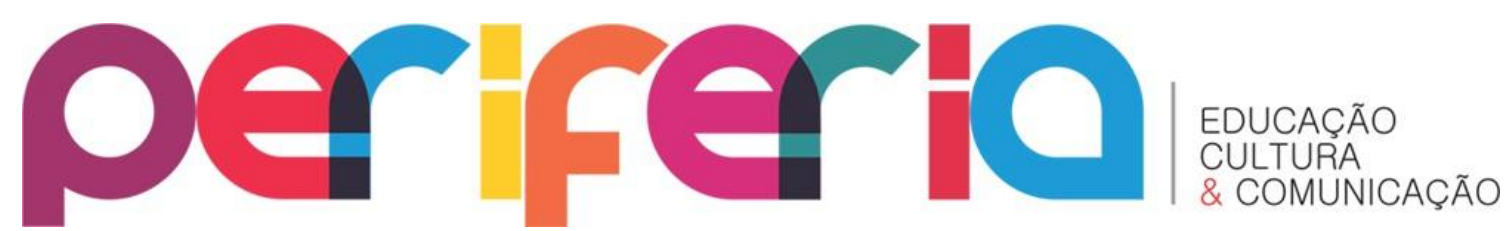

foi um avanço significativo, mas percebemos que a luta antirracista ainda está longe de terminar. Cada batalha travada, cada vitória, cada derrota, nos dá a certeza que os caminhos percorridos, mesmo sendo de duras pedras, não são trilhados solitariamente; ao contrário.

\section{REFERÊNCIAS}

ALVES, Nilda. Cultura e cotidiano escolar. Revista Brasileira de Educação. Rio de Janeiro, n.23, maio-ago., 2003.

CAPUTO, Stela Guedes. Educação nos terreiros: e como a escola se relaciona com crianças de candomblé. Rio de Janeiro: Pallas, 2012.

CARNEIRO, Edison. Candomblés da Bahia. Rio de Janeiro: Civilização Brasileira, 1991.

FANON, Franz. Pele negra, máscaras brancas. Salvador: EDUFBA, 2008.

FREIRE, Paulo. Ação cultural para a liberdade. Rio de Janeiro: Paz e Terra, 1984.

GOMES, Nilma Lino. Um olhar além das fronteiras: educação e relações raciais, Belo Horizonte: Autêntica, 2007.

HERNANDEZ, Leila Leite. A África na sala de aula: visita à história contemporânea. São Paulo: Selo Negro, 2008.

MACEDO, Edir. Orixás, Caboclos e Guias: deuses ou demônios? Rio deJaneiro: Universal Produções, 1987.

MACHADO DE ALMEIDA, Ronaldo Rômulo. A Universalização do Reino de Deus. Dissertação de Mestrado em Antropologia Social apresentada na UNICAMP, 1996.

MUNANGA, Kabengele. Superando o Racismo na escola. $2^{\text {a }}$ edição revisada /, organizador. - [Brasília]: Ministério da Educação, Secretaria de Educação Continuada, Alfabetização e Diversidade, 2005.

Rediscutindo a mestiçagem no Brasil: identidade nacional versus identidade negra. $3^{\mathrm{a}}$ ed. Belo Horizonte: Autentica, 2008.

Negritude: usos e sentidos. $3^{\text {a }}$ ed. Belo Horizonte: Autêntica, 2012.

ORO, Ari Pedro. Neopentecostais e afro-brasileiros: quem vencerá esta guerra? Debates do $N E R, \quad$ Porto Alegre, ano 1, $\mathrm{n}^{\circ} 1, \quad$ p. 10-36, novembro/1997 < http://seer.ufrgs.br/index.php/debatesdoner/article/view/2686/1502>. Acesso em 19/10/2017.

SARMENTO, Manuel Jacinto. Infância, corpo e educação física. Cadernos de Formação RBCE. 2015. 


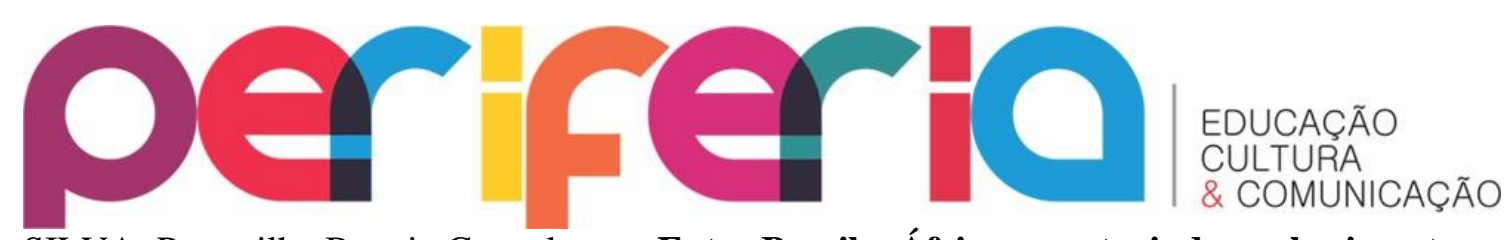

SILVA, Petronilha Beatriz Gonçalves e. Entre Brasil e África: construindo conhecimentos e militância. Belo Horizonte: Mazza, 2011.

SODRÉ, Muniz. O terreiro e a cidade: A forma social negro-brasileira. Rio de Janeiro: Vozes, 1988. 